\title{
The prevalence of high blood pressure as one of cardiovascular risk factors among women with polycystic ovary syndrome
}

\author{
Renata Michalak', Agnieszka Jagodzińska' ${ }^{2}$, Wojciech Zieleniewski ${ }^{2}$ \\ ${ }^{1}$ Department of Cardiology, Medical University of Łódź, Poland \\ ${ }^{2}$ Unit of Endocrinology, SP ZOZ MSW, Łódź, Poland
}

\section{Summary}

Background Polycystic ovary syndrome (PCOS) is one of the commonest endocrinopathy diagnosed among women mainly at reproductive age. For the first time it was described by Stein and Leventhal in 1935 and defined by two of the three findings: irregular menses (oligo-/amenorrhoea), hyperandrogenism or polycystic ovaries appearance on ultrasound, provided that other causes of androgen excess and dysovulation are excluded. PCOS is very often associated with infertility, endometrium cancer, obesity, insulin resistance, impaired glucose metabolism, higher risk for type 2 diabetes, high blood pressure, impaired lipid profile, mental illnesses and non-alcoholic liver steatosis. The presence of some of mentioned conditions may exacerbate the risk of cardiovascular events in women with PCOS $[1,2]$. The main goal of our study was to assess the frequency of hypertension among women with PCOS.

Material and methods Retrospective analysis of medical records of 213 women, age 17-42 (mean $25 \pm 6$ years). Results Twenty-two women (10\%) in examined group suffered from hypertension. The incidence of elevated blood pressure was higher among women with insulin resistance $(\mathrm{p}=0.006)$. Prevalence odds ratio $(\mathrm{OR})$ of arterial hypertension in the group with hyperprolactinaemia was 0.15 (confidence interval [CI] 0.06-0.37) and in the group with insulin resistance (OR) 1.05 (CI 0.61-1.83).

Conclusion The prevalence of hypertension among women with PCOS is higher when compared with healthy women at the same age. Thus, due to the young age of enrolled patients, it seems reasonable to recommend extension of the diagnostics of PCOS with blood pressure assessment.

key words: hypertension, polycystic ovary syndrome, cardiovascular disease

Arterial Hypertension 2015, vol. 19, no 1, pages: 19-22

DOI: $10.5603 / A H .2015 .0004$

\section{Background}

Polycystic ovary syndrome (PCOS) is one of the commonest endocrinopathy diagnosed among women mainly at reproductive age. The prevalence of PCOS is dependent on diagnostic criteria, from $9 \%$ according to the NIH Consensus 1990, up to $18 \%$ with the Rotterdam consensus 2003 [1, 2]. For the first time it was described by Stein and Leventhal in 1935 and defined by two of the three findings: irregular menses (oligo-/amenorrhoea), hyperandrogenism (clinical or/and biochemical examinations performed, if possible, in the follicular phase) or polycystic ovaries appearance on ultrasound (presence of more than 12 follicles of diameter 2-9 mm or ovarian volume greater than $10 \mathrm{~cm}^{3}$ [3], provided that other causes of androgen excess and dysovulation are excluded. Irregularity of menses is defined as 8 or less cycles per year. Hirsutism is assessed according to Ferriman-Gallwey index. The presence

Address for correspondence: Renata Michalak MD, PhD Department of Cardiology, Medical University of Łódź, Poland e-mail: renatkamichalak@gmail.com 
of hirsutism is more pronounced among Caucasian (around 70\%), than in Asian (10\%) women [1, 4]. According to the diagnostic criteria, PCOS may be divided into: "classic phenotype" PCOS characterised by hyperandrogenism and oligomenorrhoea with or without polycystic ovaries, "ovulatory phenotype" - hyperandrogenism and polycystic ovaries in normally ovulating women, "non-hyperandrogenic phenotype" - oligomenorrhoea and polycystic ovaries without overt hyperandrogenism [3]. Classic PCOS phenotype remains the most common variant of disease, with the prevalence of almost 70\% [4].

PCOS is a complex endocrine disease, and due to uncertainty about its aetiology (it is probably determined by both environmental and genetic risk factors), heterogeneous clinical presentation and despite of the detailed diagnostic description may give lots of diagnostic and treatment disturbances. Besides of typical symptoms and signs, PCOS is very often associated with infertility, cancer of endometrium, obesity (prevalence ranging from 12.5 up to $100 \%$ ), insulin resistance and compensatory hyperinsulinaemia (especially in the classic phenotype), impaired glucose metabolism, higher risk for type 2 diabetes (7.5-10\%) [5], with 5- to 10-fold higher rate of progression from impaired glucose metabolism to overt type 2 diabetes [5], metabolic syndrome, high blood pressure, impaired lipid profile (higher levels of triglycerides, LDL-cholesterol and total cholesterol and lower HDL cholesterol), mental illnesses (e.g. depression), obstructive sleep apnoea and non-alcoholic liver steatosis. The presence of the aforementioned conditions may increase risk of cardiovascular events, such as acute coronary syndrome (7-fold higher), coronary artery disease (1.5-fold higher), intracerebral stroke (2.8-fold higher). However, the risk of increased cardiovascular morbidity and mortality has not yet been fully elucidated and needs further investigation [6].

\section{Goal of the study}

The main goal of our study was to assess the frequency of hypertension among women with PCOS as one of cardiovascular diseases and acute event risk factor.

\section{Material and methods}

We performed a retrospective analysis of the medical records of 213 women. We enrolled in the study patients between 17 and 42 (mean $25 \pm 6$ years) with established diagnosis of PCOS according to the Rotterdam Consensus Criteria. We divided the study population into a group with high blood pressure (with past medical history of artery hypertension or the blood pressure above $140 / 90 \mathrm{mmHg}$ measured de novo) and a group with normal blood pressure. Blood pressure was measured twice a day, in the morning and before sleep or an ambulatory blood pressure monitoring (ABPM) was performed. Additionally, we assessed the correlation between insulin resistance, hyperprolactinaemia and artery hypertension. Data were statistically analysed using MS Office Excel and Statistica Software.

\section{Results}

Twenty-two women (10\% of examined group) suffered from hypertension. High blood pressure was found more frequently in the group with normal prolactin level $(\mathrm{p}<0.001)$. Among women with insulin resistance blood pressure was higher than in the group with normal insulin sensitivity $(\mathrm{p}=0.006)$. Prevalence odds ratio (OR) of arterial hypertension in the group of hyperprolactinaemia was 0.15 (confidence interval [CI] 0.06-0.37) and in the group with insulin resistance odds ratio (OR) was 1.05 (CI 0.61-1.83). Prevalence of high blood pressure, hyperprolactinaemia, insulin resistance, obesity, hyperlipidaemia, hyperandrogenism and hirsutism are shown in Table I.

\section{Discussion}

Hypertension is one of the most common chronic diseases worldwide. According to the World Health Organisation, arterial hypertension is defined as systolic blood pressure (SBP) above $140 \mathrm{mmHg}$ and diastolic blood pressure above $90 \mathrm{mmHg}$ [6]. A major problem associated with hypertension is its asymptomatic nature, while serious risk factors of organ damage might be found. Nowadays, high blood pressure affects around 1 billion people in the whole world and because of important links to the modern lifestyle it is considered as a disease of civilization of the XXI century [7]. Prognosis for 2015 predicts that cardiovascular diseases may cause 20 million deaths worldwide. The prevalence of hypertension varies depending on the geographical localization, socio-cultural and economic factors and usually it coexists with the level of industrialization as in the United States, Canada, Japan, Australia and most European countries. In Africa and the underdeveloped south of China the percentage of hypertension does not exceed $15 \%$ [8]. 
Table I. Prevalence of high blood pressure, hyperprolactinemia, insulin resistance, obesity, hyperlipidemia, hyperandrogenism and hirsutism

\begin{tabular}{l|c|c}
\hline Condition & $\begin{array}{c}\text { Number } \\
\text { of patients }\end{array}$ & $(\%)$ \\
\hline Artery hypertension & 22 & 10 \\
\hline Hyperprolactinaemia & 167 & 77 \\
\hline Insulin resistance & 110 & 51 \\
\hline Obesity & 74 & 34 \\
\hline Hyperandrogenism & 82 & 37 \\
\hline Hyperlipidaemia & 32 & 15 \\
\hline Hirsutism & 41 & 19 \\
\hline
\end{tabular}

The prevalence of hypertension in Western Europe and the US white population is moderate, around $15-30 \%$, while in Poland, Russia, Finland and among African Americans in the United States is large and exceeds $30 \%$. Epidemiologists say that between 2000 and 2025, the number of patients with hypertension can increase up to $60 \%[9,10]$.

One of the Polish largest studies, NATPOL III PLUS (2002) among group of 3051 people, showed that the incidence of hypertension in Poland is around $29 \%$. The frequency of high normal blood pressure rated at $30 \%$ [11-13]. There were not differences between sex (women 29\%, men 28.9\%). The prevalence of hypertension in the younger group (18-39 years) was 7.2\% (3.4\% women vs. men $11 \%, \mathrm{p}<0.05)$ in the group of $40-59$ years - 34.1\% (34\% women vs. men 34.1\%), while in group over 59 years - 57.5\% (59.9\% women vs. men 54\%) [14].

When comparing our results and younger group of women (18-39 years) from NATPOL III PLUS, we found that high blood pressure was more frequent among patients with PCOS (respectively $10 \%$ vs. $3.4 \%)$. Additionally, higher blood pressure was also clearly marked in the group with PCOS and insulin resistance compared with the group with normal glucose metabolism.

Although the data on cardiovascular events in women in the reproductive age suffering from PCOS is scarce, the available literature suggests more frequent cardiovascular diseases in classic PCOS phenotype [15]. Studies assessing an increased risk of morbidity and mortality due to cardiovascular diseases among these women are inconclusive [15]. Some of the PCOS's studies revealed an association between high blood pressure and this endocrine condition. In the North East Brazil study the prevalence of artery hypertension was 2-fold higher in women with PCOS compared with non-PCOS group $(\mathrm{p}<0.05)$ [6].
Chen and Young (2007) found that the free androgen index $\geq 19 \%$ and low level of the sex hormone binding globulin (SHBG) is associated with the increased risk of higher blood pressure [16]. In a China study [17] the prevalence of hypertension was only $1.2 \%$, however, in a group of high blood pressure and PCOS they found higher level of glucose, insulin, lipids and insulin resistance (calculated with HOMA index) and all of these differences were significant $(\mathrm{p}<0.05)$ [17].

Study of the Tunisian National Institute of $\mathrm{Nu}$ trition showed that a family history of high blood pressure was not a risk factor for the same condition in PCOS women, but patients suffering both from PCOS and hypertension had a significantly higher level of triglyceride and BMI [18].

Holte et al. (1996) in a Swedish study revealed an association between higher day-time systolic blood pressure SBP $(\mathrm{p}<0.05)$ and increased pulse rate $(\mathrm{p}<0.05)$ among PCOS group but there were not differences in diastolic blood pressure DBP $(\mathrm{p}=0.05)[19]$.

Higashi et al. (2002) found than in a group of PCOS women the nocturnal SBP did not fall by $10 \%$ or more compared with day-time SBP, which is characteristic for "non-dipper" pattern of diurnal high blood pressure. This association is probably due to endothelial impairment and corroborates with insulin resistance and waist circumference [20].

Lifelong exposure to cardiovascular risk factors such as: metabolic syndrome, type 2 diabetes, obesity, dyslipidaemia, insulin resistance and hypertension may lead to premature atherosclerosis [6]. According to Women Ischaemia Evaluation Study (WISE), women with PCOS have a large number of CVD events [15]. Greater prevalence of coronary artery calcifications in PCOS group is independent of age and BMI [21]. Vascular calcifications cause arterial stiffness and endothelial dysfunction [22]. In some studies it was shown, that endothelial dysfunction was strongly associated with higher level of androgen and insulin resistance. Group of "classic phenotype" of PCOS is considered as worse cardiometabolic profile and higher risk of cardiovascular events compared with "non-hyperandrogenic phenotype" [22]. In addition, women with PCOS have more advanced coronary artery disease (usually multivessel disease) [15].

\section{Conclusion}

The prevalence of hypertension among women with PCOS is higher than in general population at the same age. Thus, due to the young age of enrolled 
patients (mainly women between 20 and 40 years of age), it seems reasonable to recommend extension of the diagnostic of PCOS with blood pressure assessment, especially when PCOS is accompanied with obesity, insulin resistance, impaired glucose tolerance and lipid metabolism. Blood pressure should be routinely checked at each visit. Moreover, early diagnosis, proper treatment, prevention and monitoring of possible complications and organ damage caused by hypertension can contribute to a significant reduction of increased risk of cardiovascular disease.

\section{Conflict of interest}

None declared.

\section{References}

1. Azziz R., Woods K., Reyna R., Key T., Knochenhauer E., Yildiz B. The prevalence and features of the polycystic ovary syndrome in an unselected population. J. Clin. Endocrinol. Metab. 2004; 89: 2745-2749.

2. March W., Moore V., Willson K., Phillips D., Norman R., Davies M. The prevalence of polycystic ovary syndrome in a community sample assessed under contrasting diagnostic criteria. Hum. Reprod. 2010; 25: 544-551.

3. Spritzer P. Polycystic ovary syndrome: reviewing diagnosis and management of metabolic disturbances. Arq. Bras. Endocrinol. Metabol. 2014; 58: 182-187.

4. Zhang H., Guo C., Zhu F., Qu P., Lin W., Xiong J. Clinical characteristics, metabolic features, and phenotype of Chinese women with polycystic ovary syndrome: a large-scale case-control study. Arch. Gynecol. Obstet. 2013; 287: 525-531.

5. Norman R., Masters L., Milner C., Wang J., Davies M. Relative risk of conversion from normoglycaemia to impaired glucose tolerance or non-insulin dependent diabetes mellitus in polycystic ovarian syndrome. Hum Reprod. 2001; 16: 1995-1998.

6. Scicchitano P., Dentamaro I., Carbonara R et al. Cardiovascular risk in women with PCOS. Int. J. Endocrinol. Metab. 2012; 10: 611-618.

7. Monalio J., Olson J., Longstreth W. Hypertension and conquitive function: pathophysiologic effects of hypertension on the brain. Medycyna po Dyplomie 2004; 1: 88-99.
8. Kannel W. Hypertensive risk assessment, cardiovascular risk factor and hypertension. J. Clin. Hypertens. (Greenwich) 2004; 6: 393-399.

9. Lüscher T. The endothelium in hypertension: bystander, target or mediator. J. Hypertens. 1994; 12: 105-116.

10. Kawecka-Jaszcz K., Prośnik-Urbańska A., Jankowski P. Rozpowszechnienie nadciśnienia tętniczego w zależności od płci w świetle badań epidemiologicznych w Polsce. Art. Hypertens. 2007; 11: 377-383.

11. Zdrojewski T., Bandosz P., Wyrzykowski B. Nadciśnienie tętnicze w Polsce a aktualne zalecenia towarzystw europejskich w zakresie prewencji chorób układu krążenia. Terapia 2004; (07-08): 10-11.

12. Zdrojewski T., Wyrzykowski B., Szczech R. et al. Epidemiology and prevention of arterial hypertension in Poland. Blood Press. (Suppl.) 2005; 2: 6-10.

13. Zdrojewski T., Szpakowski P., Bandosz P. et al. Arterial hypertension in Poland in 2002. J. Hum. Hypertens. 2004; 18: 557-562.

14. Zdrojewski T., Bandosz P., Szpakowski P. et al. Rozpowszechnienie głównych czynników ryzyka chorób układu sercowo-naczyniowego w Polsce. Wyniki badania NATPOL PLUS. Kardiol. Pol. 2004; 61 (Suppl. IV): 15-17.

15. Hillman J., Johnson L., Limaye M., Feldman R., Sammel M., Dokras A. Black women with polycystic ovary syndrome (PCOS) have increased risk for metabolic syndrome and cardiovascular disease compared with white women with PCOS [corrected]. Fertil. Steril. 2014; 101: 530-535. Erratum in: Fertil. Steril. 2014; 101: 1791.

16. Chen M., Yang W., Yang J., Chen C., Ho H., Yang Y. Relationship between androgen levels and blood pressure in young women with polycystic ovary syndrome. Hypertension 2007; 49: 1442-1447.

17. Shi Y., Cui Y., Sun X et al. Hypertension in women with polycystic ovary syndrome: prevalence and associated cardiovascular risk factors. Eur. J. Obstet. Gynecol. Reprod. Biol. 2014; 173: 66-70.

18. Ben Salem Hachmi L., Ben Salem Hachmi S., Bouzid C et al. Hypertension in polycystic ovary syndrome. Arch. Mal. Coeur Vaiss. 2006; 99: 687-690.

19. Holte J., Gennarelli G., Berne C., Bergh T., Lithell H. Elevated ambulatory day-time blood pressure in women with polycystic ovary syndrome: a sign of a pre-hypertensive state? Hum. Reprod. 1996; 11: 23-28.

20. Higashi Y., Nakagawa K., Kimura $M$ et al. Circadian variation of blood pressure and endothelial function in patients with essential hypertension: a comparison of dippers and non-dippers. J. Am. Coll. Cardiol. 2002; 40: 2039-2043.

21. Daan N., Louwers Y., Koster M et al. Cardiovascular and metabolic profiles amongst different polycystic ovary syndrome phenotypes: who is really at risk? Fertil Steril. 2014; 102: 1444-1451.

22. Conway G., Dewailly D., Diamanti-Kandarakis E. et al. The polycystic ovary syndrome: a position statement from the European Society of Endocrinology. Eur. J. Endocrinol. 2014; 171: 1-29. 